\title{
A MODERNIZAÇÃo PELA INSTRUÇÃO PÚBLICA: \\ A EDUCAÇÃO BRASILEIRA DE 1841 A 1889, \\ A PARTIR DO SERRO/ MG
}

\author{
MODERNIZATION BY PUBLIC INSTRUCCTION: \\ THE BRAZILIAN EDUCATION FROM 1841 TO 1889, FROM SERRO/MG
}

Danilo Arnaldo Briskievicz ${ }^{1}$

\begin{abstract}
RESUMO: O objetivo principal deste estudo é demonstrar como a política educacional do governo imperial no período de 1841 a 1889 afetou o cotidiano de professores, alunos e das comunidades mais distantes da Corte, na cidade do Rio de Janeiro, em especial na cidade do Serro/MG. A análise tem como pressuposto a crítica da modernização e do progresso pela instrução pública e como esse processo afetou a atividade docente no período. A metodologia percorre dois caminhos: o primeiro, no sentido de mapear, coletar, analisar documentos originais de arquivos públicos e privados, além de ampla pesquisa de livros de autores especializados no tema; o segundo, apresentando uma versão sobre a modernidade e o progresso a partir de Talcott Parsons. O resultado esperado é uma versão sobre a instrução pública - o cotidiano escolar é nosso foco para reelaborar a compreensão da relação entre o discurso oficial das elites serranas/brasileiras e o uso da instrução pública como moeda de troca para o seu poder político e econômico.
\end{abstract}

Palavras-chave: História do Brasil. História da educação. Cotidiano escolar. Atividade docente.

\begin{abstract}
The main objective of this study is to demonstrate how the educational policy of the imperial government in the period from 1841 to 1889 affected the daily life of teachers, students and communities farthest from the Court, in the city of Rio de Janeiro, especially in the city of Serro/MG. The analysis is based on the critique of modernization and progress by public education and how this process affected teaching activity in the period. The methodology goes through two paths: the first one, in the sense of mapping, collecting, analyzing original documents from public and private archives, as well as extensive research of books by authors specialized in the subject; the second, presenting a version on modernity and progress from Talcott Parsons. The expected result is a version on public instruction - our school daily life is our focus - to re-elaborate the understanding between the official discourse of the "Serrana"/Brazilian elites and the use of public education as a bargaining chip for their political and economic power.
\end{abstract}

Keywords: History of Brazil. History of education. School daily. Teaching activity.

1 Instituto Federal de Minas Gerais. Doutor em Educação. 


\section{Introdução}

Dom Pedro II assumiu o governo do Brasil no dia 23 de julho de 1840 por causa do golpe da maioridade. No período do segundo reinado - de 1840 até a proclamação da república em 1889 - a palavra-chave para a compreensão do contexto sócio-político-econômico é a modernização. A complexidade deste período de relativa estabilidade do corpo político se revela na constante mediação do governo a fim de agradar as elites urbanas e rurais, uma vez que a economia baseou-se na agroexportação, em especial do café do Vale do Paraíba para a Europa. A região sudeste do Brasil concentrou a maior parte dos investimentos governamentais, ampliando sua malha ferroviária. Face à colocação do Brasil na nova ordem do capitalismo mundial, a escravização dos africanos passou a ser combatida tanto pelos agentes externos como a Inglaterra como dos internos, ligados aos movimentos abolicionistas.

Desde o início do século XIX houve uma efervescência das elites serranas em torno do progresso econômico centrado nas atividades agrárias, pastoris e comerciais, baseadas, ainda, na escravidão e seus ganhos financeiros. A população continuou em pleno crescimento. Isso pode ser verificado pelo comparativo entre o Censo Provincial de 1840 em que a cidade do Serro contava com 5.195 habitantes, aumentando esse número para 10.584 em 1858 a partir de dados estimativos do mesmo governo provincial (SOUZA, 1993, p. 116). Isso representa uma taxa de crescimento na ordem de 4\%. Como a educação na cidade do Serro foi afetada pelo contexto econômico e político nacional e regional? Ao que parece, a instrução pública foi escolhida pelas elites locais isso aparece nos documentos a serem analisados - como a esfera social em que a modernização do Brasil, da Comarca do Serro e da própria cidade poderia ser medida. A educação passou a conformar a modernização desejada das elites serranas. Por isso, o ponto de partida para a compreensão da educação brasileira a partir do Serro deve metodologicamente colocar-se na busca de explicar as tensões entre o atrasado e o moderno; os métodos antigos e os métodos modernos de ensinabilidade; os costumes coloniais (Ouro Preto, a capital da província de Minas Gerais era um modelo a ser superado) e os costumes 
provinciais (nesse caso, a referência é a cidade do Rio de Janeiro, modelo absoluto das elites serranas); o religioso e o secular; o masculino e o feminino; analfabetos e civilizados. A noção de modernização é importante pois tem origem na comparação entre sociedades diferentes. O Serro passava por um momento modernizador uma vez que pela educação pretendia criar e/ou aprimorar seu pertencimento ao universo ocidental e eurocêntrico, provincial e nacional podendo afirmar-se como uma cidade que conseguiu depois de muitos anos o reconhecimento de sua evolução civilizatória. A educação passou a ser considerada como uma esfera social de reprodução de um padrão de vida elitista, dinâmico, moderno, livre e poderoso. Por isso, a noção de modernização como metodologia explicativa para os dilemas vivenciados pela educação serrana é uma derivação do pensamento de Talcott Parsons (1969), criticado recentemente por confundir padrão evolutivo com ocidentalização. Por isso, a modernização contribui para explicar o fundamento das elites serranas para exigirem uma melhoria da instrução pública, ficando claro que se trata de uma explicação para a mentalidade serrana da segunda metade do século XIX, a procura de modelos evoluídos e de vanguarda em que pudessem se espelhar. A modernização serrana diz respeito, especificamente, à sua abertura - real ou fictícia - para a novidade.

Portanto, a análise da educação brasileira a partir do Serro/MG no período de 1840 a 1889 exige a compreensão dos conflitos inerentes à modernização econômica, política, social - que parte do pressuposto de que é preciso acelerar a evolução de uma determinada sociedade a fim de que ela se torne o mais semelhante possível ao seu modelo. Será que a educação conseguiu, de fato, corresponder às expectativas modernizadoras nacionais e, por extensão, serranas? Este é o problema que vamos investigar a partir da análise de documentos relativos ao cotidiano da educação serrana, das biografias de professores e professoras e de estudos e pesquisas sobre o período.

\section{O contexto geral da educação no Serro}

O período de 1702 a 1807 é o que denominamos por processo de institucionalização do jeito barroco serrano de ser. Nesse período, as dinâmicas 
de mestiçagens (PAIVA, 2013, p. 14), estavam consolidadas através do ensino espontâneo responsável pelo bom funcionamento dos ofícios mecânicos. O período de 1807 a 1840 é o período da inclusão da educação formal como parte integrante do jeito barroco serrano de ser. O período de 1840 a 1889 é o da modernização desse jeito de ser e estar no mundo. A educação formal aparece como um ponto fundamental para os projetos de crescimento econômico e político da cidade do Serro no cenário da predominância da instrução pública. Ela aparece como integrada à forma de ver o mundo das elites serranas. Por ela se reproduz, desde cedo, para as crianças e jovens recém-chegados ao mundo pelo nascimento, a importância da leitura, da escrita e das operações básicas da matemática. Dessa forma, o terceiro período pode ser melhor compreendido pela evidência de três eventos modernizadores ligados ao jeito barroco serrano de ser: o primeiro é a criação do Hospital Santa Tereza para cuidar da saúde pública; o segundo é a revitalização do adro da Matriz de Nossa Senhora da Conceição, o maior ícone do jeito barroco serrano de ser por conta de ser a memória viva do padroado; o terceiro é a construção do Cemitério Público Municipal considerado fundamental para a preservação da saúde pública e o controle das doenças provocadas pelo inadequado sepultamento nas campas das igrejas. As três obras - hospital, matriz e cemitério - explicam a modernização do jeito barroco serrano de ser, em seu constante processo de reatualização.

Em 1840, a educação formal serrana dependia totalmente do governo provincial. De fato, o que se sabe é que em 1832 o antigo professor de primeiras letras da cidade, o alfaiate e tenente Antônio Gomes Chaves, foi jubilado oficialmente pelo Conselho do Governo Provincial devido à sua idade avançada e por moléstias que Ihe impossibilitavam o magistério, recebendo metade de seus proventos $^{2}$. Há uma probabilidade de que um dos substitutos do mestre Chaves tenha sido o mestre Santos que teve sua escola funcionando no Pasto do Padilha até o final do século XIX, quando morreu velho. Outros professores remunerados pelos cofres provinciais assumiram as aulas de gramática latina e francês no Serro, como o professor José Egydio de Moura, tendo como professor de primeiras letras Ricardo Peregrino de Queirós e Dona Anna Adelaide Nunes Rabello mencionados no Almanak de 1872 (MARTINS, 1872, p. 539). No dia 03

\footnotetext{
${ }^{2}$ Arquivo pessoal Maria Eremita de Souza (24-05-1973, caderno 24).
} 
de março de 1880, essa mesma professora pública comunicou ao Inspetor da Instrução Pública da Comarca do Serro, José Maria Brandão que entraria em licença de trinta dias para fazer o exame das matérias acrescidas pelo Regulamento 84, em Diamantina, sendo substituída por Dona Tertuliana Nunes Rabello na sua escola primária de $2^{\circ}$ grau (RABELLO, 1880). Um documento da Secretaria da Inspetoria Geral da Instrução Pública de Ouro enviou um ofício datado de 04 de agosto de 1880, dirigido ao inspetor do $12^{\circ}$ Círculo Literário, José Maria Brandão, para que passasse mediante recibo para a $1^{a}$ Cadeira do $2^{\circ}$ Grau Sexo Feminino da cidade "nove exemplares do opúsculo intitulado - Leitura para Escolas - para o uso das meninas pobres" (OURO PRETO, 1880).

No Almanak de 1874 aparecem como professor de latim e francês José Coelho Tocantins de Gouvêa, de primeiras Letras do sexo masculino da primeira cadeira Veríssimo Pereira dos Reis e da segunda cadeira, vaga, e do sexo feminino Dona Anna Adelaide Nunes Rabello (MARTINS, 1874, p. 379). Em relação à Diamantina e Conceição do Mato Dentro, outras cidades que compunham a Comarca do Serro do Frio, a situação das primeiras letras aparece regular, sem reclamações em documentos oficiais. Importante ressaltar que as aulas públicas não impediam o ensino domiciliar, focado especialmente na leitura e não na escrita (FARIA FILHO; CHAMON; ROSA, 2006, p. 13).

A modernização das ideias pedagógicas brasileiras aconteceu através do Decreto no 7.247, de 19 de abril de 1879, reformulando o ensino primário, secundário e superior na capital do império, a cidade do Rio de Janeiro. A reforma Leôncio de Carvalho como é conhecida este decreto é composta de 174 itens agrupados em 29 artigos em que se propõe que a educação deve ser centrada em dois pilares, a moralidade e a higiene.

\section{O magistério dos professores}

Na segunda metade do século XIX vários professores se dedicaram à instrução pública no Serro, em seu termo, por Minas Gerais e pelo Brasil afora. Nesse sentido, a narrativa sobre os professores elucida sobremaneira como era a atividade docente no Brasil do segundo reinado. Comecemos por destacar duas escolas. A primeira era a de primeiras letras do mestre Santos nos arredores da 
cidade; foi estabelecida no lugar chamado Pasto Padilha e que depois, no início do século XX recebeu o nome de Lazareto, por abrigar, para quarentena, doentes de varíola e depois de hanseníase. A segunda escola era também de primeiras letras e de ensino secundário regida pelo professor apelidado de Chico Carangonço, na antiga Rua Direita, próxima à matriz da cidade, numa casa que foi demolida, entre a atual E. E. Ministro Edmundo Lins e a casa denominada de Vila Naninha ${ }^{3}$

Joaquim Ferreira de Salles (1879-1962), deputado e jornalista serrano relata como era o funcionamento da escola do mestre Santos. Segundo Salles (1993, p. 65-71),

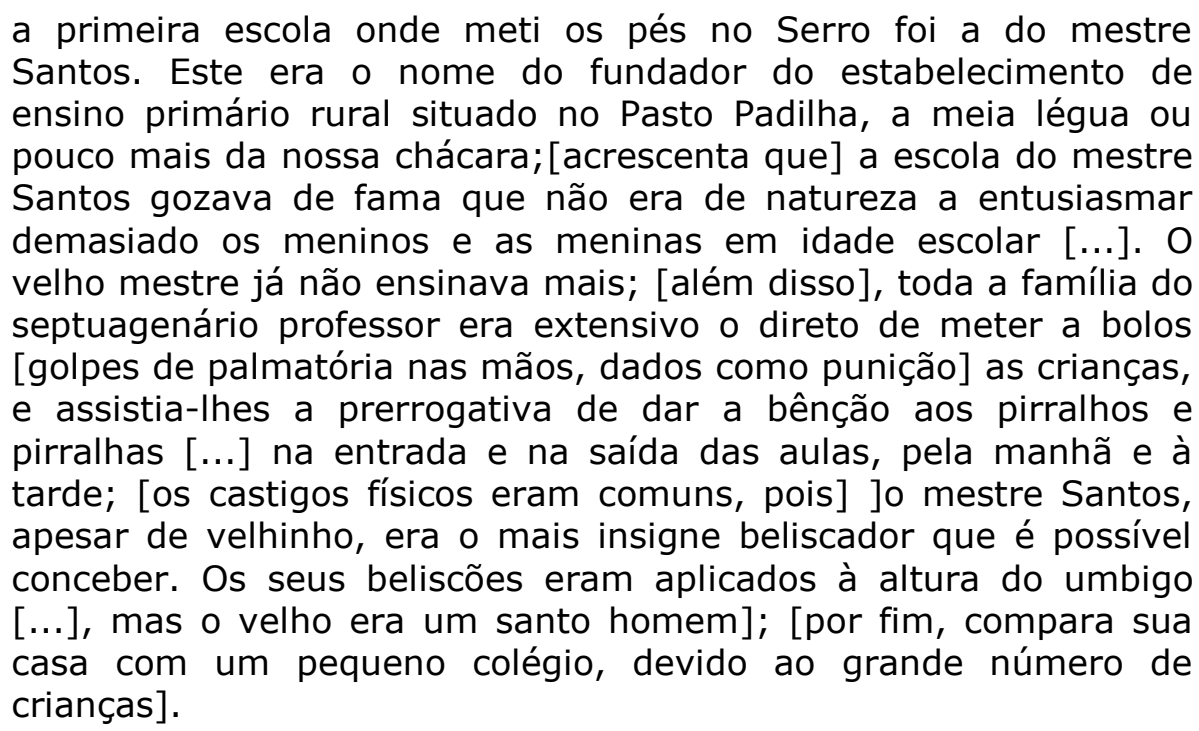

Em relação ao ensino secundário, Salles (1993, p. 176-179) explica que a "escola de Chico Carangonço era destinada a rapazinhos maiores de catorze anos [...] em consequência de praxe uniforme ou de tácito consentimento entre os pais de família do Serro"; para ele, "à hora da saída, no fim da aula, a impressão dada pelo pequeno formigueiro lembrava, não o fim das classes de uma escola primária, porém a trepidação de alunos de liceu, de curso secundário, soltos de regresso ao lar." A ausência dos nomes completos dos professores, os castigos físicos de beliscões e bolos e a disciplina que se pretendia inflexível são características dos relatos de Salles.

\footnotetext{
${ }^{3}$ Arquivo pessoal Maria Eremita de Souza (11-10-1966, caderno 11).
} 
É possível que esses professores tenham sido efetivados pela lei no 60 de 07 de março de 1837 que previa a criação três cadeiras, uma de filosofia e retórica, outra de língua francesa, geografia e história e a última de latinidade e francês (CARVALHO, 1933).

Alguns professores mantiveram suas aulas pagas pelos cofres públicos na cidade do Serro. As aulas de gramática latina ou de latinidades eram lecionadas na casa de Antônio Cândido Cruz Machado (1820-1905) para os meninos que já tivessem passado pelas primeiras letras. As aulas do curso secundário, intermediário ou de humanidades foram assumidas em 28 de abril de 1837, quando o professor teve seu diploma reconhecido: "a comissão de requerimento a quem foi presente o diploma pelo qual foi nomeado lente da cadeira de latinidades desta vila o cidadão Antônio Cândido da Cruz Machado é de parecer que se mande registrar o mesmo no livro competente"4. O funcionamento precário das aulas foi atestado pelos oficiais da Câmara Municipal em 12 de julho de 1838. Pela discussão entre os oficiais ficou registrado que se tratava de uma aula que não contava com a pontualidade do mestre, chegando a ser chamado de desleixado por abandonar os alunos a mendigarem aulas pela cidade, pelo vereador Andrade que, entretanto, foi de parecer de dar-lhe o atestado para receber seu pagamento, de acordo com a lei provincial no 108 . Na sessão da Câmara de 26 de abril de 1837, por exemplo, "indicou que se oficiasse ao delegado [de ensino] a fim de providenciar a respeito" de que há mais de um mês acha-se ausente o professor da vila ${ }^{5}$. Nascido em Ouro Branco/MG, filho de Antônio da Cruz Machado e Maria José Velasco atuou como advogado provisionado no Serro, o que é comprovado pela procuração de João Henrique Ferreira e outros que o constituíram procurador para assumir diante da Câmara os cargos de primeiro, segundo e terceiros juízes de paz do distrito do Rio Vermelho (IPHAN,1837).

O advogado José Coelho Tocantins de Gouvêa, falecido em 1896 atuou também como professor de gramática latina. Segundo Miranda (1972, p. 88), "foi professor de humanidades no Serro, tendo tido como discípulos o Dr. Joaquim Vieira de Andrade, Pedro Lessa e D. Epaminondas N. de Ávila e Silva"

\footnotetext{
${ }^{4}$ Arquivo pessoal Maria Eremita de Souza (1837, caderno 12).

${ }^{5}$ Arquivo pessoal Maria Eremita de Souza (1837, caderno 12).
} 
tendo sido deputado à Assembleia Provincial de Minas Gerais nos biênios de 1870-1872 e 1882-1883. Em 1876 atuou como vereador da Câmara Municipal, integrando a comissão de ofícios (IPHAN,1876).

É possível concluir que se tratava de uma classe pequena, com dezenove rapazes matriculados, tendo dezesseis tornados aptos a continuarem seus estudos superiores. No dia 02 de novembro de 1876 o professor Tocantins escreveu um importante registro sobre a saúde pública do Serro. Respondendo ao ofício do governo provincial, esclarece que "graças à Divina Providência, não foi este município no corrente ano invadido por epidemia alguma, sendo a mais satisfatória possível o seu estado sanitário" (GOUVÊA, 1876). A saúde pública e a educação eram problemas de primeira grandeza nesse contexto social serrano. Em relação às aulas do professor Tocantins sabe-se que por elas passaram vários serranos que partiram para o Rio de Janeiro, São Paulo e Ouro Preto para fazerem seus estudos superiores, entre eles o futuro ministro do Superior Tribunal Federal, Pedro Lessa. Em 1880, o professor Tocantins assumiu a cadeira de latim do recém-inaugurado Liceu de Artes e Ofícios do Serro, criado pela lei no 2.543, de 06 de dezembro de 1879 e que funcionou ao lado da escola do professor Chico Carangonço, no prédio alugado pelo governo provincial dos herdeiros do Barão de Diamantina.

O professor Cândido José de Senna (1843-1911) nasceu em Rio das Contas, na Bahia, onde se casou com sua primeira esposa Maria Angélica Normanha de Senna. Em 1863 morava em Januária, onde nasceu seu primeiro filho, chamado Policarpo. Por lá iniciou sua carreira de professor de primeiras letras ou de ensino primário, regendo uma escola do sexo masculino. Transferiu-se para Guanhães onde ocorreu a morte de sua primeira esposa. Ele casou-se em segundas núpcias com Maria Brasilina Coelho de Senna. Aproximadamente no ano de 1875, mudou-se para Serro Frio, continuando como professor. Em 11 de janeiro de 1876 apresentou uma reclamação à Câmara Municipal pedindo "permissão para pedir a V. S. alguma providência a fim de que os pais de família não distraiam tanto seus filhos da escola, cuja inconveniência V. S. notará no referido mapa que a esta acompanha" (SENNA, 1876). No Serro nasceu, a 11 de outubro de 1876, o seu filho Nelson Coelho de Senna. Este fez os seus estudos primários com o próprio pai e os estudos secundários com o meio irmão Policarpo, que 
havia feito seus estudos em colégios do Rio de Janeiro, manteve com o pai aulas noturnas para alfabetização de adultos em São João Evangelista onde também lecionava português, francês e geografia. A transferência do professor Cândido do Serro para São João Evangelista aconteceu em 1881 por nomeação para abertura da escola pública do sexo masculino (PIMENTA, 1966).

O professor Ângelo Ribeiro de Miranda (1866-1931) - conhecido como mestre Anjinho - nasceu em Sabinópolis/MG onde foi alfabetizado nas primeiras letras, completando seus estudos secundários no Seminário de Diamantina, cidade onde cursou a Escola Normal. Atuou como advogado provisionado pelo Tribunal de Apelação de Minas Gerais (PIRES, 2015, p. 81). Quem conta a história da escola do mestre Anjinho é Salles (1993, p. 116-117): "meu irmão José e eu fomos os dois primeiros alunos que se matricularam numa nova escola, cujo primeiro titular foi o professor Ângelo Ribeiro de Miranda"; ele era "de vinte e um ou vinte e três anos, mas inteligentíssimo e preparadíssimo" permanecendo na escola três anos; "a escola do mestre Anjinho funcionou em quatro prédios diversos." Em relação ao funcionamento da escola em vários prédios, Salles (1993, p. 118) destaca que depois de ter tido aulas na antiga Casa da Câmara, na antiga Rua Direita, mudaram-se para "uma linda casa na parte superior da cidade, com um imenso terreno onde havia espaço de sobra para o recreio dos meninos." Trata-se da antiga casa dos Carneiros, comprada pela municipalidade em 28 de novembro de 1895 de sua proprietária Júlia Carneiro da Cunha (SOUZA, 1999, p. 205), onde funcionou a Escola Normal Municipal (1900-1907), o Grupo Escolar Dr. João Pinheiro nos seus primeiros anos (inaugurado em 1907, funcionando em 1908) ao mesmo tempo que a Câmara Municipal (depois o Executivo Municipal) e, atualmente, a Câmara Municipal e a Prefeitura da cidade.

A narrativa de Salles sobre a escola do mestre Anjinho traz à lume duas questões relacionadas ao ensino público serrano que explica muitíssimo sobre a educação no Brasil na segunda metade do século XIX. O primeiro problema enfrentado era a ausência de prédios públicos especificamente criados e/ou adaptados para o pleno funcionamento de uma escola de primeiras letras que fornecesse um ambiente pedagógico e didático satisfatório, o que de certa maneira desencontrava com o princípio do higienismo da reforma Leôncio de Carvalho, de 1879. O segundo problema diz respeito à formação dos professores, 
uma vez que na visão de Salles, o mestre Anjinho era preparadíssimo. Este professor preparou-se para o exercício de sua profissão ingressando na Escola Normal de Diamantina. Por isso, diferenciava-se dos demais que assumiram suas cadeiras sem uma formação específica ou apenas por indicação política. Com o passar do tempo a exigência pela formação específica, seja por força do mercado ou da lei, obrigaria a criação de cursos normais no Serro, o mesmo ocorrendo na província de Minas Gerais.

Por fim, foi identificado outro professor que atuou no Serro. Tomás Antônio Teixeira de Gouvêa foi advogado e professor de gramática latina ${ }^{6}$ ao mesmo tempo em que servia como secretário da Câmara Municipal em 14 de abril de 1847. A informação é confirmada pelo recibo de 28 de abril de 1844: "26\$660 Recebi do Sr. Procurador João José da Silva Gouvêa a quantia acima de vinte e seis mil seiscentos e sessenta reis do meu ordenado, como Secretário da C. Municipal desde $\circ 1^{\circ}$ trimestre de abril até 24 do mesmo mês" (GOUVÊA, 1844). Sua escola funcionava na Rua das Flores, próxima ao antigo prédio da Câmara pois, no dia 15 de julho de 1845, pediu permissão para pôr um portão a sua custa em um beco unido a sua casa, uma vez que o público não se serve mais dele $^{7}$. Em 1874 respondia pela Coletoria.

Em relação aos professores da Comarca do Serro a rotina burocrática da instrução pública é confirmada por vários documentos que demonstram o trabalho desses mestres em seu cotidiano institucional. No dia 01/04/1871, foi registrada a entrega do mapa de alunos da escola pública de Nossa Senhora das Catas Altas do Mato Dentro, professor José Marques Ferreira, delegado da instrução pública Antônio Alves da Silva (MAPA..., 1871a). Em 10/04/1871, foi apresentado o mapa de alunos da escola pública do distrito do Brumado do Mato Dentro, professor Juscelino[?] de Souza Braga, delegado do distrito José A. Duarte (MAPA..., 1871b). No dia 30/07/1871, foi entregue o mapa da escola pública de Santo Antônio da Tapera, do professor interino José Jorge Mayer e Manoel Herculano Ottoni (MAPA..., 1871c).

Em 25/08/1876, a Inspetoria Geral da Instrução Pública da Província de Minas Gerais de Ouro Preto comunicou a aprovação do presidente da província

\footnotetext{
${ }^{6}$ Arquivo pessoal Maria Eremita de Souza (1975, caderno 27).

${ }^{7}$ Arquivo pessoal Maria Eremita de Souza (1975, caderno 27).
} 
da nomeação do cidadão Antônio Augusto Vieira Horta, para reger interinamente a cadeira de instrução primária elementar da freguesia de Santo Antônio da Tapera (OURO PRETO, 1876a). No dia 07/10/1876, a Inspetoria Geral da Instrução Pública da Província de Minas Gerais de Ouro Preto fez consulta sobre estado de saúde do professor e se a cadeira de Francisco Procópio de Souza Ferreira, de São Sebastião do Rio Preto ou Cemitério tem estado sem lição, sendo que a licença foi aprovada pelo prazo de noventa dias (OURO PRETO, 1876a).

No dia 30/11/1876, a Inspetoria Geral da Instrução Pública da Província de Minas Gerais de Ouro Preto comunicou de acordo com o artigo 89 e 105 do Regulamento no 70, declarar vitalício o professor de latim e francês da cidade da Conceição, José Theodoro de Souza Lima (OURO PRETO, 1876b). Em 25/12/1876, a Inspetoria Geral da Instrução Pública da Província de Minas Gerais de Ouro Preto concedeu ao professor José Manoel da Costa Camêllo a remoção que pediu da cadeira de primeiras letras na freguesia de Nossa Senhora Mãe dos Homens do Turvo para a de igual classe da freguesia de Santo Antônio do Itambé ambas desse município (OURO PRETO, 1876c). Da mesma Inspetoria veio a nomeação do professor Manoel Vieira de Pinna da cadeira de instrução primária elementar da freguesia das Dores de Guanhães a igual categoria da de Nossa Senhora Mãe dos Homens do Turvo município dessa cidade, no dia 01/02/1877 (OURO PRETO, 1877).

Em 18/05/1877, o professor público Francisco Procópio de Souza Ferreira escreveu ao inspetor da instrução pública da Comarca do Serro:

em ofício de 8 do corrente enviei a V. S. mapa ano dos alunos matriculados em minha aula exigido por esta inspetoria em ofícios de 22 de dezembro e 10 de fevereiro último, o que não remeti a mais tempo pelo motivo já exposto de incômodos de saúde. $\mathrm{Na}$ mesma data levei ao conhecimento de $\mathrm{V}$. S. que reassumi meu magistério a 7 do corrente. Estando minha aula com grande falta de utensílios como seja gramáticas, metrologias de Cássio [?], catecismos, silabários traslados ect ect e sendo aqui os meus alunos em maioria muito inteligentes não podendo começar os livros mais indispensáveis para os trabalhos escolares, por isso lembrei-me de levar ao conhecimento de V. As. a fim de ser satisfeito os meus pedidos. Deus guarde a V. As. São Sebastião do Rio Preto (Cemitério) 18 de maio de 1877 (FERREIRA, 1877). 
Em 22/04/1877, o professor Vicente Marques de Santana da escola de Dores de Guanhães recebeu de Ludgerio Gomes da Silveira delegado de instrução publica desde cadeira da Capelinha de Nossa Senhora as Dores de Guanhães quatro coleções de tratados, um [...] de gramática portuguesa, um Regulamento no 56, um regimento interno impresso de 1868 já bastante deteriorado, utensílios estes pertencentes à cadeira da mesma paróquia, sendo eles entregues para a abertura da escola (IPHAN, 1877a). No dia 05/05/1877, o professor da Freguesia de Santana de Nossa Senhora das Dores de Guanhães abriu aula (IPHAN, 1877b). Em 18/07/1880, o professor da instrução primária Manoel Vieira de Pina de São Domingos do Rio do Peixe encaminhou mapa do segundo trimestre do corrente ano (MAPA..., 1880).

Em 28/07/1880, o padre Veríssimo José de Abreu delegado encaminhou mapa do $2^{0}$ trimestre deste ano da primeira escola pública de Conceição do Serro (MAPA..., 1880b). No dia 12/10/1880, a Inspetoria Geral da Instrução Pública da Província de Minas Gerais de Ouro Preto nomeou o professor do distrito de Congonhas, termo da Conceição João C. M[?] para Santana da Tapera (OURO PRETO, 1880). Em 30/11/1880, o professor padre José de Vasconcelos Silveira da aula pública em São João do Peçanha. Em 19/03/1881, a Inspetoria Geral da Instrução Pública da Província de Minas Gerais de Ouro Preto transferiu o professor público da freguesia de Mãe do Turvo termo do Serro Januário Júlio Baracho para São José dos Paulistas, sendo que sua nomeação foi publicada em 22/01/1881 (OURO PRETO, 1881a).

Em 31/03/1880 apresentou o mapa da escola municipal do Ribeirão da Saia e Cócos, o professor Antônio marques de Oliveira, criada em 20 de março de 1880 , sendo que o professor foi nomeado para a cadeira em 20/03/1880 (IPHAN, 1880a) e continuava professor da mesma localidade até 31/03/1883 quando enviou o mapa dos alunos da escola municipal do comércio de Nossa Senhora das Dores do Cocós, professor Antônio Marques de Oliveira. Atestado assinado por Leonício Teixeira da Silva e Francisco da Costa Rodrigues:

Atestamos e sendo necessário juraremos aos Santos Evangelhos com como o atual professor deste comércio, o Sr. Antônio Marques de Oliveira, tem sido assíduo em seu magistério, moderado para com seus discípulos, estimando-os afagando-os e fornecendo com jantar aos de mais longe. Atestamos mais que neste trimestre 
houve falha da mais parte dos alunos pela nímia pobreza dos pais por não os poder vestir e sustentar para frequentar a aula. E por ser este pedido sabermos ser público e nos se apresentado o seu diário, o mandamos passar e somente o assinamos (SILVA; RODRIGUÊS, [1883]).

No dia 05/04/1881, a Inspetoria Geral da Instrução Pública da Província de Minas Gerais de Ouro Preto nomeou o professor interino da cadeira de primeiro grau da freguesia de São Francisco de Assis do Paraúna, termo da Conceição, Godofredo Ferreira Carneiro, por ato do dia 19 de março. Em 18/05/1881, a Inspetoria Geral da Instrução Pública da Província de Minas Gerais de Ouro Preto, nomeou o professor Francisco Xavier de Figueiredo para a $2^{a}$ cadeira de S. Antônio do Itambé (OURO PRETO, 1881b).

No dia 02/01/1882, escreveu Josephino José Gonçalves professor particular de instrução pública da povoação de São José do Quilombo, deste município, que sendo sua escola subvencionada pelo o cofre desta ilustríssima Câmara com o ordenado anual de centro e vinte mil réis, e estando findo o trimestre começado em julho pretérito, data em que o suplicante começou ali o ensino, tendo cumprido escrupulosamente seus deveres como verá V. S. dos mapas juntos quer por isso receber a importância do mesmo trimestre pelo dito cofre; e por isso requer a $\mathrm{V}$. S. se digne de lhe mandar fazer o referido pagamento na forma do costume (GONÇALVES, 1882).

Concluindo, no dia 28/02/1886 foram apresentados os mapas de frequência da escola do Ribeirão de Santo Antônio do Mosquito, distrito do Serro, 10 trimestre de fevereiro a março de 1886 regida por Pedro da Cunha Ferreira Rabello (MAPAS..., 1886). No dia 24/12/1887, foi entregue o mapa da escola municipal de instrução primária do Deliz regida pelo professor Manoel Simões de Oliveira Júnior sendo que na mesma data pedia licença de 20 dias para ver os familiares no Vau, distante a quatro léguas.

\section{O magistério das professoras}

Francisca Paula foi a primeira professora do Serro. A sua atuação foi autorizada pela Câmara Municipal e ficou registrada em ata da sessão de 28 de agosto de 1847: "Dona Francisca Paula apresenta título de professora primária 
do sexo feminino; é registrado e a Câmara faz público por edital estar ela em exercício"8. A respeito desta primeira professora nada mais se sabe: se veio de outra cidade da província de Minas Gerais, por conta de um pedido de transferência; se era serrana; onde teria funcionado sua aula; quanto tempo permaneceu no magistério.

Em 15 de maio de 1878, o inspetor da Comarca do Serro lançou um edital para concurso para preenchimento da vaga da segunda cadeira de instrução primária do sexo feminino da cidade do Serro, tendo por examinadores Dr. Ernesto Pio dos Mares Guia e Dr. Joaquim de Carvalho Drummond, segundo o Regulamento no 56, de 10 de maio de 1867 , sobre os quais as candidatas deveriam estar totalmente preparadas para as provas (COMARCA DO SERRO, 1878).

O que sabe do resultado do concurso público é que no 22 de julho de 1879 formou-se uma comissão da Câmara Municipal encarregada de fazer a estatística para criação de duas escolas municipais uma no Gambá para os meninos de ambos os sexos no então chamado quarteirão número um da cidade e outra no Pasto do Padilha para os meninos do quarteirão número oito. Segundo os dados levantados pela comissão interna da Câmara, havia uma demanda muito grande por instrução pública nos extremos da cidade. Assim, existiriam no primeiro quarteirão mais de 52 meninos em idade escolar e no oitavo quarteirão 32 em iguais condições.

O parecer final da comissão emitiu um parecer para fossem criadas as ditas escolas públicas municipais e propôs para o quarteirão número um como professora Ana Procópia da Costa, filha do de Abraão da Costa Veloso, que também exerceu a profissão de professor na cidade. Para o quarteirão número oito foi proposto o nome de Bibiana Augusta de Queiroz, filha do mestre Santos, provavelmente já falecido naquela data. Cada uma das professoras municipais receberia por ano uma a gratificação de $300 \$ 000^{9}$.

Na sessão da Câmara Municipal do dia 22 de julho de 1879, a instituição incluiu no seu orçamento as quantias despendíveis com essas escolas de instrução primária para ambos os sexos, sendo enviado um ofício para o Palácio

\footnotetext{
${ }^{8}$ Arquivo pessoal Maria Eremita de Souza (Caderno 27).

${ }^{9}$ Arquivo pessoal Maria Eremita de Souza (05-04-1988, caderno 152).
} 
da Presidência da Província de Minas Gerais para aprovação (SERRO, 1879). O mapa estatístico da instrução primária municipal do distrito da cidade do Serro durante o segundo semestre do ano de 1885 mostrou que as duas professoras atuavam em suas escolas: Ana Procópia na sede de sua escola na Rua General Osório, no antigo Gambá no 57 com 46 alunos de ambos os sexos matriculados, no trimestre de julho a setembro. Estavam adiantados nos estudos 20, sendo que o documento confirma que esta escola foi criada por esta Câmara a 15 de março de 1879, pagando-se anualmente 300\$000. Já Bibiana Augusta de Queirós trabalhava no Pasto Padilha, sendo sua escola com sede na Chácara Boa Vista com frequência diária de 75 meninos e meninas, de julho a setembro; e 98 de outubro a dezembro sendo adiantados nos estudos $58^{10}$.

A professora Bibiana Augusta de Queirós, herdeira da escola de seu pai (PIRES, 2015, p. 54), o mestre Santos, trabalhava no Pasto Padilha, na mesma antiga escola mencionada por Joaquim de Salles, na Chácara Boa Vista. Não consta se a mesma professora tivesse o curso de normalista. O que ela herdou da escola de seu pai foi a habilidade com as crianças e a exata compreensão dos regulamentos da instrução pública do Brasil, da província e da cidade do Serro. Sua escola funcionava plenamente desde o ano de sua aprovação no concurso e sua nomeação para a escola criada pela Câmara Municipal em 1879. Em 30 de junho de 1881 continuava a atender o quarteirão número oito o que pode ser confirmado pelo mapa entregue à inspetoria da Comarca do Serro (IPHAN, 1881a). Nesse documento, consta que ela regia a escola para meninos e meninas, de primeiras letras ou, como se dizia na época, para o ensino primário elementar. No dia 12 de janeiro de 1882, por algum motivo que não se explica, a professora se esqueceu de enviar à inspetoria municipal duas cópias da ata dos exames de seus alunos inscritos. Ela foi advertida pela Câmara que solicitou outra cópia uma vez que uma ficaria arquivada no município e outra seguiria para Ouro Preto. Os exames obrigatórios dos alunos eram realizados na primeira quinzena do mês de dezembro de cada ano e os examinadores eram escolhidos pelos vereadores da Câmara Municipal. Lavrava-se uma ata do exame que comprovava oficialmente o funcionamento da escola, o nível de aprendizado dos alunos e a qualificação das professoras para o exercício de suas funções.

${ }^{10}$ Arquivo pessoal Maria Eremita de Souza (1987, caderno 121) 
Para receber o pagamento por seu trabalho na escola do oitavo quarteirão do Serro, a professora Bibiana precisava comprovar trimestralmente o funcionamento da sua escola com os mapas dos alunos matriculados. Entregues os mapas, solicitava o pagamento de seus ordenados. A remuneração era recebida trimestralmente, ou seja, a professora recebia o seu salário quatro vezes ao ano, numa soma total de 300\$000 reis. É o que ela fez no dia 17 de outubro de 1887 quando escreveu, justificou e assinou a solicitação:

Diz Bibiana Augusta de Queiroz, professora municipal do $8^{\circ}$ quarteirão desta cidade que, tendo vencido o terceiro trimestre do corrente ano, e desejando a suplicante seja paga dos seus honorários correspondentes ao referido trimestre vem requerer a V. S. se digne mandar pelo Sr. Secretário dessa ilustre Câmara passar-Ihe a guia de pagamento para ser apresentada ao procurador e este a cumprir. A suplicante apresenta mapa trimestral em duplicata a fim de ler o competente destino com o qual prova-se ter no referido período a sua escola uma frequência de 122 alunos (QUEIROZ, 1887).

A outra professora municipal Ana Procópia da Costa teve sua história ligada com a professora Bibiana Augusta de Queirós desde o concurso público até a nomeação. A professora Ana trabalhou no atendimento de alunos e alunas do quarteirão número um do Serro, denominado Gambá. No dia 30 de junho de 1880 sua escola funcionava regularmente. O atestado foi dado pelo Dr. Ernesto Pio dos Mares Guia, presidente interino da Câmara Municipal da cidade do Serro: "atesto que a professora da Escola Municipal do $1^{\circ}$ quarteirão desta cidade D. Anna Procópia da Costa cumpriu os deveres de seu cargo durante o trimestre de abril a junho que hoje finda" (GUIA, 1880). No mesmo documento se lê que Dona Ana assinou o recibo de uma das parcelas de seu ordenado anual de 300\$000 réis: "recebido do procurador da Câmara desta cidade o Ilmo. Sr. Carlos da Cunha Pereira a quantia de setenta e cinco mil reis 75\#000 de meu ordenado do $2^{\circ}$ trimestre vencido até a presente data" (GUIA, 1880). Em 30 de junho de 1881 a mestra Ana apresentou o mapa dos alunos matriculados em sua escola pública. Em 04 de julho de 1881, o delegado da instrução pública do Serro atestou o funcionamento da sua escola por conta da entrega do mapa que constavam matriculados 65 alunos (IPHAN, 1881b).

A situação dos alunos da escola pública de Dona Ana exigia que a Câmara Municipal atuasse no sentido de manter a frequência dos mesmos. Um dos 
motivos das faltas constantes era a falta de roupas para irem à escola. A falta de material escolar também contribuía para a evasão escolar. Por isso, em 29 de outubro de 1880 a Câmara Municipal por seu procurador repassou à professora o valor de $200 \$ 000$ réis para adquirir roupa, pena e tinta para os meninos pobres. A quantia foi recebida no dia 12 de dezembro de 1880 e gasta com o que se mandou e a professora teve sua prestação de contas aprovada (SERRO, 1880).

A mestra Ana também era obrigada pelos regulamentos oficiais a realizar na primeira quinzena do mês de dezembro os exames de seus alunos por uma comissão escolhida pela Câmara Municipal. Isso ocorreu no dia $1^{0}$ de dezembro de 1883, às onze horas da manhã, em sua residência que era o mesmo lugar onde as aulas aconteciam durante todo o ano (IPHAN, 1883). A história da mestra Ana na educação mudou bastante em 1907 com a inauguração do Grupo Escolar Dr. João Pinheiro. Ela não conseguiu seu cargo de professora. Tornou-se servente da mesma escola, o que é confirmado pelo registro oficial (ESCOLA DR. JOÃO PINHEIRO, 1908, p. 3, 37).

A mais reconhecida mestra serrana foi Cristina Amélia de Queirós Queiroga (c.1837-1920). Filha de Bernardino José de Queiroga Júnior (1800-1866) que foi advogado, vereador, deputado provincial e presidente da província de Minas Gerais em 1848. Ele casou-se com Maria Salomé de Queirós Queiroga. Maria Salomé de Queirós Queiroga morou na Casa da Arca, tradicional edificação serrana, hoje desaparecida, na antiga Rua da Cadeia, atual Rua Padre João Moreira ${ }^{11}$. Segundo Souza (1999, p. 239-237), "a 3 de setembro de 1785, a casa pertencia ao sargento-mor Félix pereira do Lago e sua mulher D. Maria Angélica de Jesus, a célebre Maria do Ouro Fino, tia do inconfidente Rolim." Na primeira metade do século XIX a "a casa era propriedade do sargento-mor Roberto Mascarenhas de Vasconcelos Lobo, filho do descobridor dos diamantes, Bernardo da Fonseca Lobo." Depois residiu na casa o filho do Barão de Diamantina Francisco José de Vasconcelos Lessa - "o capitão Henrique Lessa que exerceu vários cargos públicos no Serro." Consta que a Casa da Arca foi fundada para

11Segundo Souza (1999, p. 256), "fez seus primeiros estudos com a famosa mestra Cristina que se tornou sua protetora e grande amiga" tornando-se o fundador do Colégio Nossa Senhora da Conceição do Serro, que antes funcionou como orfanato. Nascido no Serro em 1873 e falecido em 1947. A sua casa ficava na mesma rua da antiga casa da mestra Cristina, onde também funcionou a primeira sede do colégio. 
"recolher moças e meninas desamparadas" sendo que o "Papa Pio VI, sabedor de suas altas virtudes religiosas e caritativas, enviou-lhe uma bênção apostólica especial." A mãe da mestra Cristina, Maria Salomé, encabeçou, em 06 de abril de 1831, a lista das mulheres que apoiaram com dinheiro e suas joias o levante de Teófilo Ottoni na Vila do Príncipe contra a as mudanças no governo do Brasil. Ela contribuiu com $100 \$ 000$ réis e possivelmente foi ela mesma quem redigiu o documento, "lamentando a fraqueza de seu sexo que as impedia de empunhar armas" oferecendo "espontaneamente suas joias, seus serviços, quando necessários."

A família da mestra Cristina era o que podemos designar por tradicional família serrana da elite do século XIX: participante da política como forma de ampliação de seu poder financeiro local, aderindo à educação como forma de ampliar ainda mais o capital cultural familiar para alcançar os melhores postos nos serviços públicos da Comarca do Serro e da província de Minas Gerais, ligada profundamente ao padroado através das obras de caridade.

Mestra Cristina fez seu curso de normalista na Escola Normal de Ouro Preto $^{12}$. Voltando ao Serro para morar com suas tias e primas por volta de $1870^{13}$. Seu nome aparece no recibo no 54, de 22 de abril de 1872, da Câmara Municipal, fazendo-Ihe pagamento de três dias de trabalho do escravo Antônio, alugado para participar de obras públicas (SERRO, 1872). O mesmo se repete em recibos de no 43 e 48, datados de 24 de junho de 1872, para obras da revitalização do adro da matriz de Nossa Senhora da Conceição. Enquanto as tias e primas moravam na antiga Casa da Arca, a mestra Cristina preocupou-se em reformar o edifício que se tornou sua residência e depois a sua escola particular

\footnotetext{
12Segundo Pedruzzi (2016, p. 12-13), "a criação da Escola Normal de Ouro Preto na primeira metade do século XIX constitui elemento de um projeto civilizatório nacional cuja construção se buscava após a independência do Brasil. Dessa forma, a partir de um plano de instrução pública, o governo brasileiro pretendia situar o recém-criado Império no rol das nações ditas "modernas" e "civilizadas". [...] A Escola Normal de Ouro Preto, por sua vez, foi criada mediante o artigo 70 da lei no 13, no dia 28 de março de 1835, sendo a primeira Escola dessa natureza instituída em Minas Gerais, na então capital da província, a cidade de Ouro Preto. Contudo, a referida instituição é marcada por períodos descontínuos de atividade: efetivamente estabelecida apenas em 1840 - cinco anos após a sua criação legal -foi fechada dois anos depois e reaberta em 1847. Em 1852 a Escola é novamente fechada, tornando à atividade somente quase vinte anos depois, em 1872. Foi com a lei no 1.769 de 1871, que a reabertura da Escola Normal de Ouro Preto tornou-se definitiva no contexto do século XIX".

${ }^{13}$ Arquivo pessoal Maria Eremita de Souza (caderno 3)
} 
de ensino primário superior. É o que confirma o registro da primeira sessão da Câmara Municipal do dia 21 de julho de 1879 em que ela apresenta uma petição: "D. Christina Amélia de Queiroga pedindo licença para reconstrução de sua casa para depositar madeira na rua e para construir uma rampa em frente da mesma casa"; segue-se o parecer do encarregado da fiscalização João Victor de Sousa, autorizando a reedificação na quinta sessão do dia 26 de julho de 1879 (SERRO, 1879).

A obra de reedificação da casa da mestra Cristina foi rápida. Como de costume, em 04 de dezembro de 1880, a comissão examinadora escolhida pela Câmara Municipal realizou os exames das alunas da aula pública de instrução pública primária superior dirigida pela professora normalista Dona Cristina Amélia de Queiroga (IPHAN, 1880b).

A história da mestra Cristina se confunde com as mudanças na educação serrana. Em 1904, as primeiras quatro irmãs Filhas da Caridade de São Vicente de Paulo chegaram ao Serro para assumirem o Hospital Santa Tereza e ensinarem para as meninas pobres da comunidade. Ficaram hospedadas primeiramente na antiga Casa da Arca com os Queiroga. Depois, mudaram-se para a casa da mestra Cristina. O resultado foi que em 1921, na residência dela, dada em testamento antes de sua morte em 1920 para a irmandade de Santa Tereza, mudou-se para lá o Colégio Nossa Senhora da Conceição. Por outro lado, a mestra Cristina ocupou o cargo de professora (ESCOLA DR. JOÃO PINHEIRO, 1908, p. 10) no recém-criado Grupo Escolar Dr. João Pinheiro, inaugurado em 1907, e que iniciou suas atividades em 1908. O grupo de professoras que atuava na escola da mestra Cristina precisavam prestar contas de suas atividades para a Inspetoria Municipal uma vez que recebia subvenções para seu funcionamento, apesar de se tratar de uma escola particular.

$\mathrm{Na}$ Comarca do Serro outras mestras dedicaram suas vidas à instrução pública. É importante registrar que a naturalização da presença da mulher nas escolas faz parte de um longo processo de emancipação feminina da obrigatoriedade da vida privada e que se amalgama com o reconhecimento social da mulher em seu papel de acolhimento, paciência, cuidado e afinidade com a maternidade. Nesse sentido,

A educação brasileira registra com especificidade em suas páginas a história da inserção das mulheres no magistério. História que se 
inscreve em um cenário de mudanças nos modos de vida social dos homens - ocupantes legítimos do espaço público nos anos finais do século XIX - e das mulheres, que à época estavam em busca de alternativas de inserção social fora do espaço doméstico. [...] A princípio, esta conquista aconteceu lentamente e em conformidade com a organização social, política e econômica. Mais tarde, no entanto, registrou-se um processo de feminização do magistério que contou, entre outras coisas, com o advento das escolas de formação docente - as escolas normais - criadas no final do século XIX como alternativa para a formação de professores. [...] Nesse cenário de mudanças, o culto à domesticidade se apresentava como uma forma de valorização da função feminina de construção dos vínculos entre o espaço público, compreendido como espaço de produção social e o espaço doméstico, entendido como espaço de reprodução - biológica e ideológica - da sociedade. Assim, de acordo com esse imaginário, cabia à mulher uma dupla tarefa: a de reprodução biológica da espécie humana e a de reprodução ideológica dos interesses sociais em cada época. Esta última deveria ser exercida através da inculcação, nos filhos e filhas, dos comportamentos esperados do futuro cidadão e da futura mãe de família. Cabia à mulher, portanto, a responsabilidade com a manutenção de uma família saudável no mais amplo sentido e, para isso, ela deveria dedicarse com esmero à formação e conservação dos vínculos familiares, pelos quais era responsável (FREIRE, 2011, p. 239-241)

No quadro geral da citação acima, podemos inscrever a rotina crescente da inserção das mulheres no magistério. Nosso objetivo é demonstrar como o surgimento da mulher no magistério se dá pari passu com as transformações sociais brasileiras, em especial, na Comarca do Serro. Em 02/10/1872, a Inspetoria Geral da Instrução Pública da Província de Minas Gerais de Ouro Preto, nomeou Dona Salvina Ferreira Maia para reger primeiramente a cadeira de instrução primária do sexo feminino da freguesia de Santana dos Ferros, município do Carmo de Itabira, criada pela lei no 1876, 15 de julho último (OURO PRETO, 1872a). No dia 18/10/1873, foi entregue o mapa dos alunos da freguesia de Itapanhoacanga, da cadeira do sexo feminino regida pela professora Francisca Carolina Andrade (IPHAN, 1873). Em 07/07/1876, foi enviada uma carta do inspetor da Comarca para o delegado de instrução do Rio Vermelho para o inspetor da Comarca sobre edital a ser fixado na porta da igreja sobre cadeiras do sexo masculino e feminino (IPHAN, 1876). No dia 11/03/1872, a Inspetoria Geral da Instrução Pública da Província de Minas Gerais de Ouro Preto declara que não aceitou a nomeação a professora nomeada da instrução primária do 
sexo feminino da freguesia de São Miguel e Almas, D. Mariana de Assis Pereira da Cunha, sem explicar os motivos (OURO PRETO, 1872b).

Em 28/05/1877, a Inspetoria da Comarca do Serro reuniu num mesmo pacote várias comunicações e recibos: da professora do Peçanha pedindo impressos para escola; recibo de Maria Cândida de Jesus, de São Gonçalo do Rio das Pedras, declarando ter recebido impressos; recibo de livros da professora da escola do Milho Verde Joaquina Angélica Ferreira Campos (COMARCA DO SERRO, 1877).

No dia 01/04/1880, foi enviada para a Inspeção da Comarca do Serro o mapa da escola particular em Santo Antônio do Rio do Peixe, da professora Maria Júlia da Costa Botelho (IPHAN, 1880c). Em 12/07/1880, Maria Cândida Soares, professora da Freguesia de Santo Antônio do Rio Abaixo, termo da Conceição, enviou mapa de sua escola do trimestre decorrido de abril a julho do corrente ano (IPHAN, 1880d). No dia 05/08/1880, foi enviado o mapa da professora da primeira escola do sexo feminino de Conceição do Serro (IPHAN, 1880e). Em 01/10/1880, foi enviado o mapa da aula pública do sexo feminino de Morro do Pilar da professora D. Rita Oliveira da Circuncisão pelo delegado Jorge Benedicto Ferreira (IPHAN, 1880f). No dia 06/10/1880, o padre Veríssimo José de Abreu delegado da Conceição encaminhou o mapa do terceiro trimestre da escola do sexo feminino regida pela professora D. Maria Cândida Gomes Lages (IPHAN, $1880 \mathrm{~g})$.

Uma correspondência da professora do Rio do Peixe ao então Inspetor da Comarca do Serro chama a atenção pela polidez e assertividade da comunicação:

Ilmo. Sr. José Maria Brandão Rio do Peixe, 8 de $8 \mathrm{br} 01880$.

Desejo que V. S. já se ache restabelecido do incômodo que sofreu de um pé, eu e o Modesto visitamos-lhe e a exma. família respeitosamente. Recebi os livros para escola, de cujas remeto-Ihe o recibo que $V$. S. exigiu e juntamente vão os mapas deste trimestre e o certificado para $V$. S. fazer visar e entregar ao mesmo portador. Sou com alta consideração. De V. S. respeitadora e obrigada criada. Thomázia Flora Diamantina Pires (PIRES, 1880).

Em 01/10/1880, o delegado Luiz Beltrão da Silva do Milho Verde encaminha para do terceiro trimestre da instrução primária do sexo feminino regida pela professora pública Joaquina Angélica Ferreira Campos (IPHAN, 1880h). No dia 
17/12/1880, Vicente Lopes de Figueiredo [delegado] encaminha mapa e ata de exames da aula de D. Gabriela Afoncina Pires, de Rio Vermelho (IPHAN, 1880i).

A exigência de prestar contas sobre os conhecimentos necessários para o exercício do magistério fez com que no dia 24/05/1881 a Inspetoria Geral da Instrução Pública da Província de Minas Gerais de Ouro Preto despachou sobre pedido das professoras da cidade de Conceição D. Maria Cândida Gomes Lages e D. Maria Carolina de Magalhães em que pedem prorrogação do prazo que lhe foi marcado para mostrarem-se habilitadas na forma do regulamento no 84 a fim de que sejam pelas peticionárias devidamente documentadas com atestados médicos e das autoridades da Instrução Pública em conformidade com a Circular de 04 do corrente mês, que provem os motivos alegados que as impedirão de cumprir aquela exigência do regulamento nas provas ultimamente marcadas (IPHAN, 1881). A exigência foi confirmada em Circular datada de 04/05/1881 segundo a qual os professores das vilas e cidades do seu círculo que não são vitalícios ou habilitados na forma do regulamento no 84 que para continuarem na regência das cadeiras do $2^{\circ}$ grau deverão requerer o quanto antes ao governo novo prazo para mostrarem-se habilitados para o respectivo ensino fazendo acompanhar suas petições de documentos comprovativos dos justos motivos que Ihe obstavam cumprir esse dever nos prazos anteriores. No caso das professoras da cidade de Conceição do mato Dentro, apenas Maria Carolina de Magalhaes conseguiu o adiamento do prazo para prestar exames.

O magistério feminino era fiscalizado não somente no cotidiano das aulas, na obrigatoriedade de escrituração dos documentos oficiais. O comportamento social era frequentemente observado: se elogiável, as professoras mantinham seu cargo. Se indecoroso para o exercício da função nas localidades, abria-se um processo administrativo. O caso da professora Dona Joaquina Angélica Augusta Ferreira Campos é emblemático para demonstrar o qual fiscalizada era a moralidade das professoras no magistério.

No dia 15/06/1881, a Inspetoria Da Inspetoria Geral da Instrução Pública da Província de Minas Gerais de Ouro Preto, enviou ofício ao inspetor da Comarca do Serro para que apurasse as:

Diversas queixas contra a professora do sexo feminino da freguesia do Milho Verde D. Joaquina Angélica Augusta Ferreira Campos, não só relativamente as suas poucas habilitações para o 


\begin{abstract}
exercício do magistério, mas seu procedimento que afirmam ser irregular e escandaloso. Compreende V. S. todo o zelo que deve haver da parte daqueles a cujo cargo está a instrução do ensino, para que o magistério se vá expurgando de indivíduos sem idoneidade profissional e, sobretudo, daqueles que por sua moralidade duvidosa tornam-se uma verdadeira calamidade pelas maus exemplos que podem dar aos discípulos que the são confiados, e também o critério e exemplo [...] em aceitarem-se informações muitas vezes, nascidas por interesses inconfiáveis ou inimizades particulares. Desejando que as providências que tenha de tomar em relação a cadeira do Milho Verde sejam as da mais estrita justiça, recomendo a V. S. que, reunindo as autoridades e pessoas fidedignas daquela localidade me informe com urgência do que houver decidido (OURO PRETO, 1881c).
\end{abstract}

Sobre a resolução do processo administrativo da professora do Milho Verde os documentos se calaram.

\title{
Referências
}

[MAPA da escola pública de Santo Antônio da Tapera]. Minas Gerais: Arquivo IPHAN, 1871c. Documento 57, caixa 13.

[MAPA de alunos da escola pública de Nossa Senhora das Catas Altas do Mato Dentro]. Minas Gerais: Arquivo IPHAN, 1871a. Documento 164, caixa 23.

[MAPA de alunos da escola pública do distrito do Brumado do Mato Dentro]. Minas Gerais: Arquivo IPHAN, 1871b. Documento 165, caixa 23.

[MAPA do $2^{\circ}$ trimestre da primeira escola pública de Conceição do Serro]. Minas Gerais: Arquivo IPHAN, 1880b. Documento 102, caixa 5.

[MAPA do segundo trimestre de São Domingos do Rio do Peixe]. Minas Gerais: Arquivo IPHAN, 1880a. Documento 89, caixa 3.

[MAPAS de frequência da escola do Ribeirão de Santo Antônio do Mosquito]. Minas Gerais: Arquivo IPHAN, 1886. Documento 14, caixa 13.

IPHAN. Documentos de Câmara. Minas Gerais: Arquivo IPHAN, 1873. Documento 68 , caixa 31.

IPHAN. Documentos de Câmara. Minas Gerais: Arquivo IPHAN, 1876. Documento $156,96,176,137,98,146$, caixa 30.

IPHAN. Documentos de Câmara. Minas Gerais: Arquivo IPHAN, 1876. Documento 95, caixa 30. 
IPHAN. Documentos de Câmara. Minas Gerais: Arquivo IPHAN, 1877a. Documento 49, caixa 24.

IPHAN. Documentos de Câmara. Minas Gerais: Arquivo IPHAN, 1877b. Documento 62, caixa 24.

IPHAN. Documentos de Câmara. Minas Gerais: Arquivo IPHAN, 1880a. Documento 22, caixa 20.

IPHAN. Documentos de Câmara. Minas Gerais: Arquivo IPHAN, 1880b. Documento 35, caixa 10.

IPHAN. Documentos de Câmara. Minas Gerais: Arquivo IPHAN, 1880c. Documento 103, caixa 9.

IPHAN. Documentos de Câmara. Minas Gerais: Arquivo IPHAN, 1880d. Documento 90, caixa 5 .

IPHAN. Documentos de Câmara. Minas Gerais: Arquivo IPHAN, 1880e. Documento 101, caixa 5.

IPHAN. Documentos de Câmara. Minas Gerais: Arquivo IPHAN, $1880 f$. Documento 34, caixa 9.

IPHAN. Documentos de Câmara. Minas Gerais: Arquivo IPHAN, 1880g. Documento 105, caixa 5.

IPHAN. Documentos de Câmara. Minas Gerais: Arquivo IPHAN, 1880h.Documento 48, caixa 8.

IPHAN. Documentos de Câmara. Minas Gerais: Arquivo IPHAN, 1880i. Documento 93, caixa 5.

IPHAN. Documentos de Câmara. Minas Gerais: Arquivo IPHAN, 1883. Documento 12 , caixa 11.

IPHAN. Documentos de Câmara. Minas Gerais: Arquivo IPHAN,1881. Documento 156 , caixa 21.

IPHAN. Documentos de Câmara. Minas Gerais: Arquivo IPHAN,1881a. Documento 24, caixa 22.

IPHAN. Documentos de Câmara. Minas Gerais: Arquivo IPHAN,1881b. Documento 29, caixa 20.

IPHAN. Documentos de Câmara. Minas Gerais: Arquivo IPHAN, [1837]. Documento 84, caixa 22.

CARVALHO, Teófilo Feu de. Instrução pública, primeiras aulas e escolas de Minas Gerais. 1721-1860. Revista do APM, Belo Horizonte, v. 24, p. 345-391, 1933. 
SERRO. Câmara Municipal. [Primeira sessão da Câmara Municipal do dia 21 de julho de 1879]. Minas Gerais: Arquivo IPHAN, 1879. Documento 17, 128, caixa $22,24$.

SERRO. Câmara Municipal. [Recibo no 54, de 22 de abril de 1872]. Minas Gerais: Arquivo IPHAN, 1872. Documento 193, caixa 17.

SERRO. Câmara Municipal. [Sessão do dia 22 de julho de 1879]. Minas Gerais: Arquivo IPHAN, 1879. Documento 14, caixa 24.

SERRO. Câmara Municipal. [Sem título]. Minas Gerais: Arquivo IPHAN, 1880. Documento 29, caixa 10.

COMARCA DO SERRO. [Edital para concurso para preenchimento da vaga da segunda cadeira de instrução primária do sexo feminino da cidade do Serro]. Minas Gerais: Arquivo IPHAN, 1878. Documento 7, caixa 13.

COMARCA DO SERRO. Inspetoria. [Sem título]. Minas Gerais: Arquivo IPHAN, 1877. Documento 51, caixa 24.

ESCOLA DR. JOÃO PINHEIRO. Livro de posses e anotações. Serro: Escola Dr. João Pinheiro, 1908.

FARIA FILHO, Luciano de; CHAMON, Carla Simone; ROSA, Walquíria Miranda. Educação elementar: Minas Gerais na primeira metade do século XIX. Belo Horizonte: Editora UFMG, 2006.

FERREIRA, Francisco Procópio de Souza. [Ofício ao inspetor da instrução pública da Comarca do Serro]. Minas Gerais: Arquivo IPHAN, 1877. Documento 50, caixa 24.

FREIRE, Eleta de Carvalho. Mulher no magistério: uma história de embates entre espaço público e espaço privado. Revista Lugares de Educação, Bananeiras, v. 1, n. 2, p. 239-256, jul.-dez. 2011. Disponível em:

http://periodicos.ufpb.br/ojs2/index.php/rle. Acesso em: 27 mar. 2019.

GONÇALVES, Josephino José. [Sem título]. Minas Gerais: Arquivo IPHAN, 1882. Documento 12 , caixa 17.

GOUVÊA, José Coelho Tocantins. [Registro sobre a saúde pública do Serro]. Minas Gerais: Arquivo IPHAN, 1876. Documento 161, caixa 30.

GoUVÊA, Tomás Antônio Teixeira. [Recibo]. Minas Gerais: Arquivo IPHAN, 1844. Documento 179, caixa 17.

GUIA. Ernesto Pio dos Mares. [Atestado]. Minas Gerais: Arquivo IPHAN, 1880. Documento 142, caixa 23.

MARTINS, Antônio de Assis. Almanak administrativo civil e industrial da Provincia de Minas Geraes do Anno de 1872 para servir no de 1873. Ouro Preto:

Typographia do Echo de Minas, 1872. Disponível em: 
https://babel.hathitrust.org/cgi/pt?id=uc1.\$b710200. Acesso em: 23 mar. 2019.

MARTINS, Antônio de Assis. Almanak administrativo civil e industrial da Provincia de Minas Geraes do Anno de 1874 para servir no de 1875. Ouro Preto:

Typographia do J. F. de Paula Castro, 1874. Disponível em:

https://babel.hathitrust.org/cgi/pt?id=uc1. $\$$ b710201; view=2up;seq=8. Acesso em: 23 mar. 2019.

MIRANDA, Aluízio Ribeiro de. Serro: três séculos de história. Belo Horizonte: Imprensa Oficial, 1972.

OURO PRETO. Inspetoria Geral da Instrução Pública da Província de Minas Gerais de Ouro Preto. [Aprovação do presidente da província da nomeação do cidadão Antônio Augusto Vieira Horta]. Minas Gerais: Arquivo IPHAN, 1876a. Documento $67,72,73$, caixa 24.

OURO PRETO. Inspetoria Geral da Instrução Pública da Província de Minas Gerais de Ouro Preto. [Declarar vitalício o professor de latim e francês da cidade da Conceição, José Theodoro de Souza Lima]. Minas Gerais: Arquivo IPHAN, 1876b. Documento 76, caixa 24.

OURO PRETO. Inspetoria Geral da Instrução Pública da Província de Minas Gerais de Ouro Preto. [Concede ao professor José Manoel da Costa Camêllo a remoção que pediu da cadeira de primeiras letras na freguesia de Nossa Senhora Mãe dos Homens do Turvo]. Minas Gerais: Arquivo IPHAN, 1876c. Documento 70, caixa 24.

OURO PRETO. Inspetoria Geral da Instrução Pública da Província de Minas Gerais de Ouro Preto. [Nomeação do professor Manoel Vieira de Pinna]. Minas Gerais: Arquivo IPHAN, 1877. Documento 59, caixa 24.

OURO PRETO. Inspetoria Geral da Instrução Pública da Província de Minas Gerais de Ouro Preto. [Nomeação do professor do distrito de Congonhas]. Minas Gerais: Arquivo IPHAN, 1880. Documento 166, caixa 21.

OURO PRETO. Inspetoria Geral da Instrução Pública da Província de Minas Gerais de Ouro Preto. [Transferência do professor público da freguesia de Mãe do Turvo]. Minas Gerais: Arquivo IPHAN, 1881a. Documento 159, 160, caixa 21.

OURO PRETO. Inspetoria Geral da Instrução Pública da Província de Minas Gerais de Ouro Preto. [Nomeação Godofredo Ferreira Carneiro e Francisco Xavier de Figueiredo]. Minas Gerais: Arquivo IPHAN, 1881b. Documento 158, 161, caixa 21.

OURO PRETO. Inspetoria Geral da Instrução Pública da Província de Minas Gerais de Ouro Preto. [Nomeação Salvina Ferreira Maia]. Minas Gerais: Arquivo IPHAN, 1872a. Documento 23, caixa 4.

OURO PRETO. Inspetoria Geral da Instrução Pública da Província de Minas Gerais de Ouro Preto. [Nomeação Mariana de Assis Pereira da Cunha]. Minas Gerais: Arquivo IPHAN, 1872b. Documento 55, caixa 24. 
OURO PRETO. Secretaria da Inspetoria Geral da Instrução Pública. [Ofício dirigido ao inspetor do $12^{\circ}$ Círculo Literário]. Minas Gerais: Arquivo IPHAN, 1880.

Documento 32, caixa 100.

PAIVA, Eduardo França. Escravidão, dinâmicas de mestiçagens e o léxico iberoamericano. Perspectivas - Portuguese Journal of Political Science and International Relations, Portugal, n. 10, p. 11-26, jun. 2013.

PARSONS, Talcott. Sociedades: perspectivas evolucionárias e comparativas. São Paulo: Pioneira, 1969.

PEDRUZZI, Jumara Seraphim. A Escola Normal de Ouro Preto: instituição e formação docente no contexto educacional mineiro do século XIX (1835-1889). 2016. Dissertação (Mestrado Educação). - Universidade Federal de Ouro Preto, Ouro Preto, 2016.

PIMENTA, Dermeval José. A mata do Peçanha, sua história e sua gente. Belo Horizonte: [s.n.], 1966.

PIRES, Maria de Lourdes Moreira. Valores do Serro: uma coletânea de perfis serranos. Contagem: [s. n.], 2015.

PIRES, Thomázia Flora Diamantina. [Correspondência]. Destinatário José Maria Brandão Rio do Peixe. Rio Peixe, 8 abr. 1880. Documento 107, caixa 5.

QUEIROZ, Bibiana Augusta. [Solicitação de pagamento]. Minas Gerais: Arquivo IPHAN, 1887. Documento 149, caixa 32.

RABELLO, Anna Adelaide Nunes. [Comunicado ao inspetor da Instrução Pública da Comarca do Serro]. Minas Gerais: Arquivo IPHAN Serro, 1880. Documento 67, caixa 100.

SALLES, Joaquim de. Se não me falha a memória. 2. ed. São Paulo: Instituto Moreira Salles, 1993.

SENNA, Cândido José. [Reclamação à Câmara Municipa/]. Minas Gerais: Arquivo IPHAN, 1876. Documento 35, caixa 24.

SILVA, Leonício Teixeira; RODRIGUES, Francisco da Costa. [Atestado]. Minas Gerais: Arquivo IPHAN, [1883]. Documento 25, caixa 9.

SOUZA, José Moreira de. Cidade: momentos e processos: Serro e Diamantina na formação do norte mineiro no século XIX. São Paulo: Marco Zero, 1993.

SOUZA, Maria Eremita de. Aconteceu no Serro. Belo Horizonte: BDMG, 1999. 
